\title{
Structural Investigation of Amorphous $\mathrm{xLi}_{2} \mathrm{O} . \mathrm{xWO}_{3} \cdot(1-2 \mathrm{x}) \mathrm{B}_{2} \mathrm{O}_{3}$ Correlated with its Physical Properties
}

\author{
Ali Abou Shama \\ Physics Department, Faculty of Science, Ain Shams University, 11566 \\ Abbassia, Cairo, Egypt
}

\begin{abstract}
The system $\mathrm{Li}_{2} \mathrm{O}-\mathrm{WO}_{3}-\mathrm{B}_{2} \mathrm{O}_{3}$ were prepared with equal molar ratios of both $\mathrm{Li}_{2} \mathrm{O}$ and $\mathrm{WO}_{3}$ by the usual rapid quenching technique. From the analysis of $X$-ray diffraction data (using a Mo-source of wavelength $\lambda=0.709 \AA$ ), it was found that for $0.0 \leq x \leq 0.25$ the systems formed are crystalline, while for $x \geq 0.30$, glassy formed systems are obtained. The glassy phases are investigated by analyzing the experimental radial distribution function RDF in both short range order (SRO) and medium range order (MRO) regions. The structural derived information's from $R D F$ analysis in the two regions are significant and promising. The first nearest neighbor distance which is due to $B-O$ correlations had an extended distance (1.30-1.499) $A$. The presence of $\mathrm{Li}_{2} \mathrm{O}$ in that amorphous matrix in the present ratio can modify the $\mathrm{BO}_{3}$ units to $\mathrm{BO}_{4}$ ones. The second nearest neighbor of $\mathrm{W}$-O bonds were arranged in form of distorted $W_{6}$ of a dispersed bond length (1.712-2.149) A. Both of B-B and O-O correlations are of smaller scattering weights and are observed as included shoulders within a main representative peak. The presence of bridging and nonbridging oxygen's was detected inside MRO range. The building units of $B-O$ containing non-bridging oxygen's (NBO) was detected in the range ( 3.099$3.25) \AA$, while those including bridging oxygen (BO) was observed in the range (3.489-3.788) A. The activation energy and electrical conductivity for the studied samples are measured and supplied for these structural collected data [12] to give a good correlation in between.
\end{abstract}

\section{Introduction:}

Colored glasses can generally be divided into two classes according to whether the generation of color centers is reversible or irreversible. Both classes have specific applications, the most prominent being the reversible darkening of sunglasses [1,2] and the irreversible coloring of utility glasses [3, 4]. Lithium borate tungstate glasses also have a color center of both types. A reversible photo-chromic blue coloration has been observed in the presence of hydrogen and was later attributed to the formation of tungsten bronzes $\mathrm{H}_{\mathrm{x}} \mathrm{WO} 3$ [5]. A 
wide spread set of very different borate glasses with optical, super-ionic conductivity, and other technologically interesting properties are currently produced [6]. The optimization of such properties as a function of composition and other preparation parameters requires a good knowledge of the microscopic glassy structure. A good precise knowledge of the structure and properties of $\mathrm{B}_{2} \mathrm{O}_{3}$ based glasses and melts is increasingly required from both fundamental and industrial points of view and, in particular the structure of borate glasses at high temperature is still controversial [7]. Among the binary borate glasses, alkali borate glasses have long been paid considerable attention by many researchers because of the "borate anomaly "in the compositional dependence of some physical properties. The structure of alkali borate glasses have been extensively studied by XRD, NMR, Raman spectroscopy, ....etc [7].

The wide applications of $\mathrm{WO}_{3}$ introduced in this glassy lithium-borate system opened a new broad range of technological interests for more industrial findings for these amorphous materials and also their evolved crystalline phases. The lithium tungstate borate glasses are considered as new candidates as laser active materials, provided one can have efficient energy transfer mechanism into long-life lasing states [8]. Also, many still prospective are in using $\mathrm{WO}_{3}$ and its bronzes in the construction of buildings, in order to control the passage of the solar energy through windows and to conserve a good level of climatization inside the building in comparison with the outside environment [9-11].

The aim of this work is to study the structure of amorphous $\left(\mathrm{a}-\mathrm{Li}_{2} \mathrm{O}-\right.$ $\mathrm{WO}_{3}-\mathrm{B}_{2} \mathrm{O}_{3}$ ) using $\mathrm{XRD}$, in the percentage range of (17.5-33.75) $\mathrm{WO}_{3}$ mole $\%$ and to explore the roles of both $\mathrm{W}$-atoms as well as Li-ions in the formed network structure. The determination is also correlated with the other measured physical properties (such as electrical conductivity, activation energy, ,...etc) . Also this study will throw more light on these ternary glass systems which have still limited publications concerned with their structural information's in both short range order ( SRO) and medium range order (MRO) regions.

\section{RDF Formulation Analysis:}

The total structure factor of a glass is given as $[7,16]$,

$$
S(K)=\frac{\left\{I(K)-\left\langle\left\langle f^{2}\right\rangle-\langle f\rangle^{2}\right]\right\}}{\langle f\rangle^{2}}
$$

where $I(K)$ is being the scattered corrected X-ray intensity of the atomic species constituting the given specimen, $f$ is the atomic scattering factor, 
$K=4 \pi \sin \theta / \lambda$ is the magnitude of the scattering vector. The term $\left\langle\left\langle f^{2}\right\rangle-\langle f\rangle^{2}\right\rfloor$ is known as the Laue diffraction. This Laue term is of more significance at small angles $(2 \theta)$ of scattering. The observed $S(K)$ is related to the deviation from the average number density $\rho_{0}$ by a sine transform as $[7,16]$

$$
S(K)=4 \pi / K \int_{0}^{\infty} r\left[\rho(r)-\rho_{0}\right] \sin (K r) d r
$$

where, $\rho(r)$ is the atomic density as a function of the radial distance $r$. Here

$$
\rho_{0}=\rho N / A \times 10^{24}
$$

where, $\rho$ is the sample density in $\mathrm{gm} / \mathrm{cm}^{3}, N$ is the Avogadro's number, $A$ is being the sample atomic weight. RDF is given as

$$
4 \pi r^{2} \rho(r)=r G(r)+4 \pi r^{2} \rho_{0}
$$

where, $G(r)$ is the reduced RDF, so

$$
\begin{aligned}
G(r) & =4 \pi r\left[\rho(r)-\rho_{0}\right]= \\
& =\frac{2}{\pi} \int_{0}^{\infty} K[S(K)-1] e^{-\alpha^{2} K^{2}} \sin (K r) d K
\end{aligned}
$$

$4 \pi r^{2} \rho_{0}$ is of asymptotic form and $\alpha^{2}$ is the disordering parameter of value $\approx 0.01 \AA^{2}$ mainly used to reduce the effect of spurious details in the high $\mathrm{K}$-range in the measured data. The applied software programs are taken from the program package implemented at LURE-France after the needed modifications to be in suitable form for X-ray diffraction (XRD) data [16]. 


\subsection{Sample preparation:}

The samples were prepared by the normal melt quenching technique method of the used constituents $\left(\mathrm{Li}_{2} \mathrm{O}, \mathrm{WO}_{3}, \mathrm{~B}_{2} \mathrm{O}_{3}\right)$ as a raw materials [12].

\subsection{XRD Experimental setup:}

The present data were collected by using Philips (X'pert MPD) diffractometer using the Bragg-Brentano para-focusing technique. Highly monochromated Mo radiation (wavelength $=0.709 \AA$ ) was used . The step scan mode was applied in the $2 \theta$-range $\left(4-115.65^{\circ}\right)$. The step size $\left(\Delta 2 \theta=0.04^{\circ}\right)$ and the counting time was $10 \mathrm{sec}$. for each reading. The corresponding accessible maximum scattering vector magnitude, $\mathrm{K}$, was $15.0 \AA^{-1}$. The air scattering was avoided by a suitable applied arrangement of XRD system. The receiving and divergence slits were properly chosen in both small and large $2 \theta$-ranges, in order to improve the qualities of data collected.

\section{Results and Discussion:}

The collected intensity of all the investigated samples was corrected for the polarization, absorption and background $[13,14]$. The corrected intensity was normalized in order to convert it into electron units (e.u.) resulting finally on the structure factor $\mathrm{S}(\mathrm{K})$. The application of Mo-source in this study permits a good resolution in both the reciprocal (K-space; $\mathrm{K}=4 \pi \sin \theta / \lambda)$ with $\mathrm{K}_{\max }=15 \AA^{-1}$ and real space (R-space). Fig.(1) shows the structure factor, $\mathrm{S}(\mathrm{K})$, versus K. Fig. 2 gives the radial distribution function, RDF, against the radial distance, R. Figures 3 and 4 are supplied by Doweidar [12]. In these two figures the change in activation energy and $\log \sigma$ is plotted versus $\mathrm{WO}_{3}($ mole $\%)$ at a constant temperature.

From the first four samples having $\mathrm{WO}_{3}(17.5,20,22.5,30) \mathrm{mole} \%$, in the $\mathrm{S}(\mathrm{K})$ versus $\mathrm{K}$, one can observe the presence of two main composite structural peaks centered around 2.0 and $4.0 \AA^{-1}$. A sharp diffraction peak is observed at nearly $0.5 \AA^{-1}$ and this peak is absent in the first sample having $17.5 \mathrm{~mole} \%$ of $\mathrm{WO}_{3}$. The appearance of this peak at this position is meaningless because its significant position is in the range of 1.0-1.75 $\AA^{-1}$ [7]. Another important observation is the evolution of another broad intense peak at about $6.0 \AA^{-1}$ in the fourth sample (having $30 \mathrm{~mole} \%$ of $\mathrm{WO}_{3}$ ) and also a small shift to longer $\mathrm{K}$ with the increase of $\mathrm{WO}_{3}$ mole\% in the second peak which means an increase in the order in the MRO region. The last two samples (having $\mathrm{WO}_{3}=32.5$ and $33.75 \mathrm{~mole} \%$ ) had the same $\mathrm{S}(\mathrm{K})$ trend and their main peaks are observed at 2.0,4.75 and $8.4 \AA^{-1}$ respectively which indicates an appreciable shift in the high $\mathrm{K}$ for the second and third peaks. The first peak of $\mathrm{S}(\mathrm{K})$ in the high $\mathrm{WO}_{3}$ mole\% samples had a good Gaussian form compared to other peaks which indicates to 
the increased order of correlated atomic pairs with the increase of $\mathrm{WO}_{3}$ mole $\%$ and the first sharp diffraction peak ( FSDP) is of lower intensity and is shifted to higher $\mathrm{K}$ values. Many of the $\mathrm{S}(\mathrm{K})$ peaks can be decomposed to more than one peak which means that more than one correlated atomic pair are incorporated inside both the SRO and MRO regions of both $\mathrm{S}(\mathrm{K})$ and $\mathrm{RDF}(\mathrm{R})$ ). Table (1) tabulates the $\mathrm{S}(\mathrm{K})$ peak positions for the given set of samples.

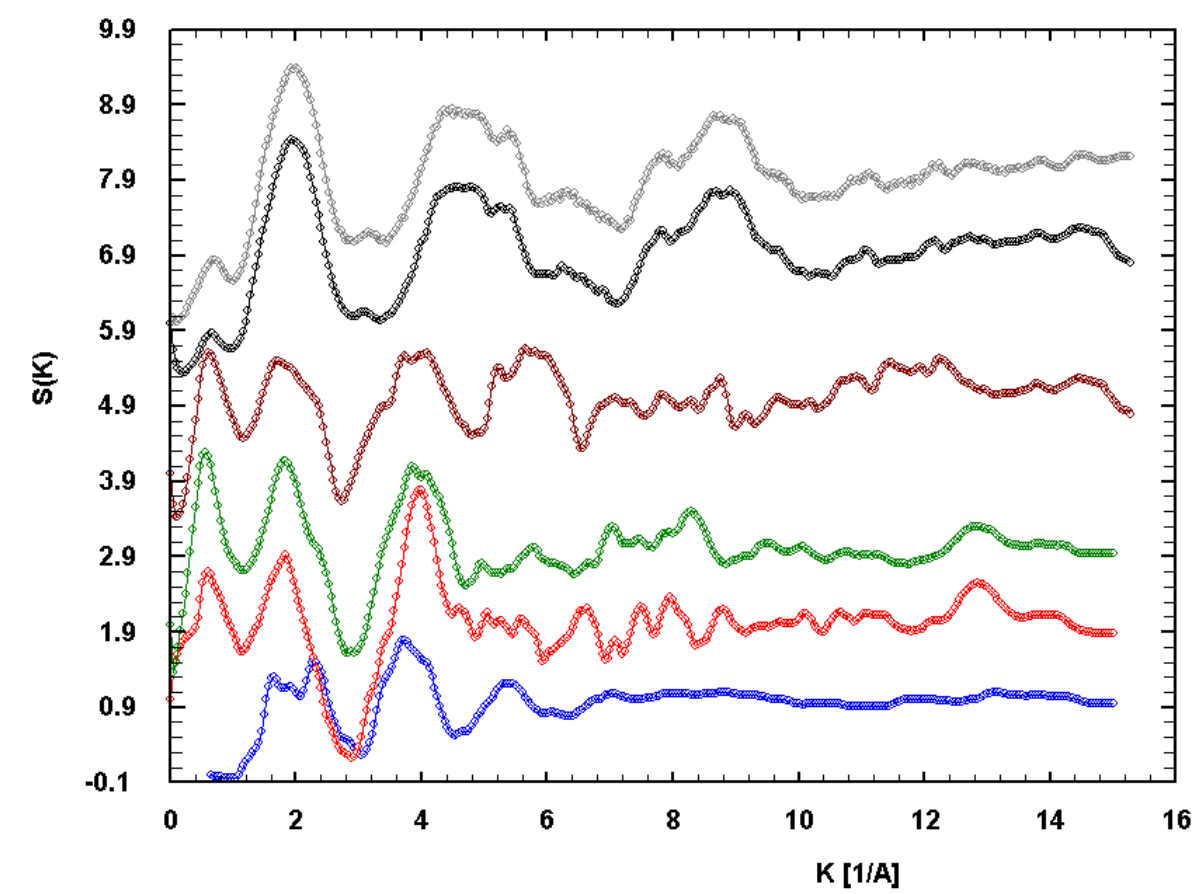

Fig.(1): The total structure factor $S(K)$ versus $K$ for the six samples investigated.

Table(1): The $\mathrm{S}(\mathrm{K})$ peak positions for the investigated samples of $\mathrm{a}-\mathrm{Li}_{2} \mathrm{O}-\mathrm{WO}_{3}-\mathrm{B}_{2} \mathrm{O}_{3}$

\begin{tabular}{|c|c|c|c|c|c|}
\hline Sample & $\mathrm{K}_{1} \AA^{-1}$ & $\mathrm{~K}_{2} \AA^{-1}$ & $\mathrm{~K}_{3} \AA^{-1}$ & $\mathrm{~K}_{4} \AA^{-1}$ & $\mathrm{~K}_{5} \AA^{-1}$ \\
\hline $\mathrm{W}(17.5 \mathrm{~mol} \%)$ & $2.0(1.4,2.4)$ & 3.75 & 5.35 & $\ldots \ldots$ & $\ldots \ldots$ \\
\hline $\mathrm{W}(20.0 \mathrm{~mol} \%)$ & 2.0 & 4.0 & 6.60 & 7.5 & 8.0 \\
\hline $\mathrm{W}(22.5 \mathrm{~mol} \%)$ & 2.0 & 4.0 & 5.55 & 6.90 & 8.30 \\
\hline $\mathrm{W}(30 \mathrm{~mol} \%)$ & 2.0 & 4.0 & 6.0 & $\ldots \ldots$ & 8.6 \\
\hline $\mathrm{W}(32.5 \mathrm{~mol} \%)$ & 2.0 & 4.6 & $\ldots \ldots$ & 7.9 & 8.8 \\
\hline $\mathrm{W}(33.75 \mathrm{~mol} \%)$ & 2.0 & 4.6 & $\ldots \ldots$ & 7.9 & 8.8 \\
\hline
\end{tabular}


The Fourier transform of the $\mathrm{S}(\mathrm{K})$ leads to the radial distribution function in real space. Fig.(2) shows the main built basic structural units. Now we discuss the finding of the main basic structural units in each sample according to its $\mathrm{WO}_{3} \mathrm{~mole} \%$; the first sample containing $17.5 \mathrm{WO}_{3}$ mole $\%$ have corresponding largest amount of $\mathrm{B}_{2} \mathrm{O}_{3}(65 \mathrm{~mole} \%)$, and due to borate anomalies[15] its basic structural units will be changed inside both the SRO and MRO. The first nearest neighbor is located at $1.486 \AA$ of coordination number about 3.0 which belongs to B-O bonds. The next nearest neighbor is observed at $2.15 \AA$ having coordination number of about 5.0 and this peak is attributable to $\mathrm{W}-\mathrm{O}$ correlations arranged in the form of $\mathrm{WO}_{5}$ (distorted octahedrons). The third peak is seen at $2.65 \AA$ which is due to $\mathrm{O}-\mathrm{O}$ correlations of coordination number of $\sim 1.85$. The next peak centered at nearly $3.299 \AA$ is due to B-O pairs inside the boroxol group of non-bridging oxygen (NBO) and these $\mathrm{B}-\mathrm{O}$ connected units are built of $\mathrm{BO}_{3}$ planar units. Also these $\mathrm{BO}_{3}$ units each of which is not forming equilateral triangle; $\mathrm{B}-\mathrm{O}$ are of different distances. A highly stretched peak which is observed at $\sim 3.90 \AA$ of coordination number 4.09 which reveal the presence of $\mathrm{B}-\mathrm{O}$ correlations of bridged oxygen types (BO) in the deformed $\mathrm{BO}_{4}$ tetrahedrons. The asymmetry of $\mathrm{B}-\mathrm{O}$ distances inside the boroxol group is due to the role of $\mathrm{Li}_{2} \mathrm{O}$ as a modifier in the matrix $[7,17]$.

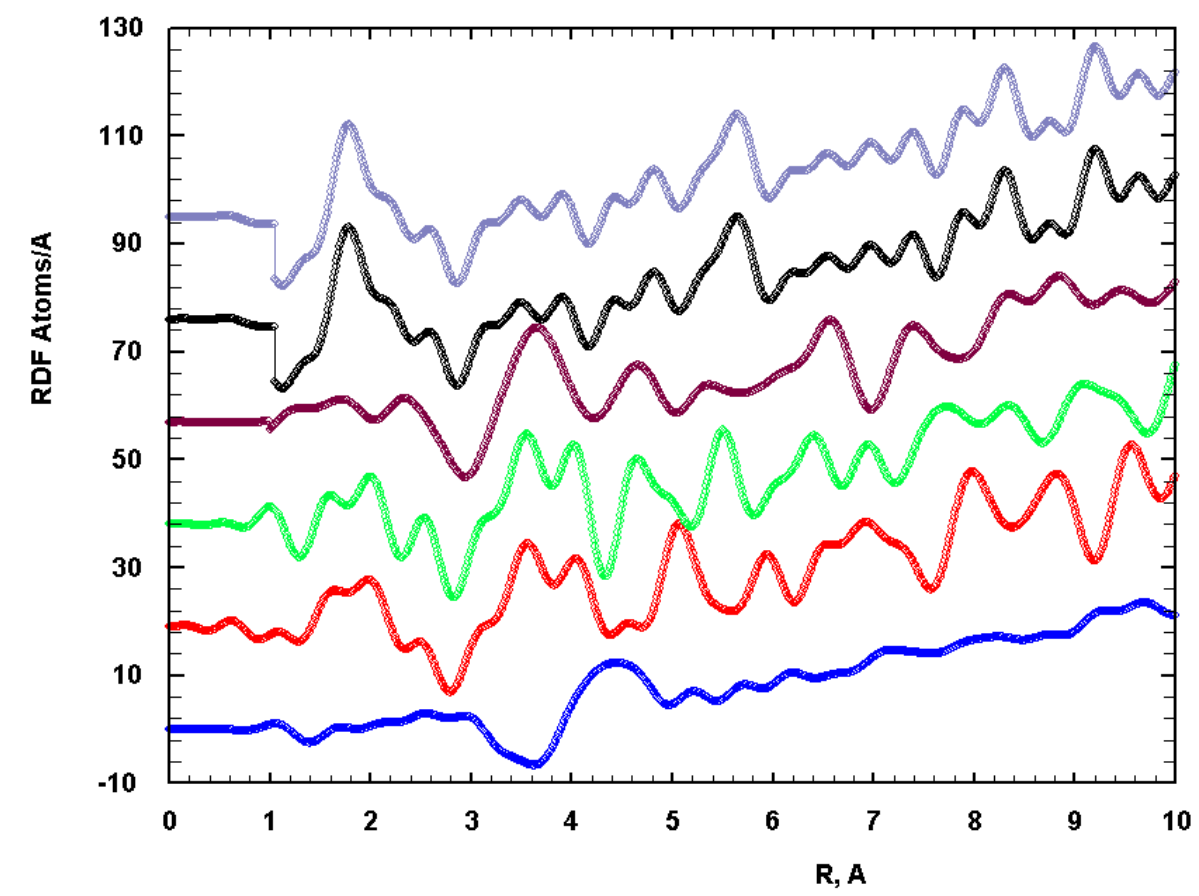

Fig.(2): The RDF against $\mathrm{R}$ in the real space is shown for the studied samples. 
For the second sample containing $20 \mathrm{WO}_{3}$ mole $\%$, the first main peak as well as the second one are of composite structure (convoluted of more than one peak, more than one atomic pair is included). The first maximum is observed at $\sim 1.499 \AA$ which belongs to $\mathrm{B}-\mathrm{O}$ bonds arranged in the form of $\mathrm{BO}_{4}$. The conversion of $\mathrm{BO}_{3}$ in the first sample to $\mathrm{BO}_{4}$ in the second one clearly shows the role of $\mathrm{Li}_{2} \mathrm{O}$ in modifying the $\mathrm{BO}_{3}$ units to $\mathrm{BO}_{4}$ tetrahedral form. The arranged tetrahedral $\left(\mathrm{BO}_{4}\right)$ is distorted which means that there is a difference in the $\mathrm{B}-\mathrm{O}$ bond lengths inside the tetrahedron. The second coordination sphere is located around $2.0 \AA$ and is also highly distorted and is revealing the presence of $\mathrm{W}-\mathrm{O}$ pairs in the form of extended $\mathrm{WO}_{6}$ octahedra. A deep shoulder is observed at $2.44 \AA$ and of coordination number about 2.58 , this shoulder is due to $\mathrm{B}-\mathrm{B}$ correlations. The second main peak is at 3.581 which is preceded by a shoulder at $3.136 \AA$ and is followed by a peak at $4.0 \AA$. This second main peak may indicate the existence of super-structural units of bridging oxygen (BO) type linked pairs beside to those of NBO found at $3.136 \AA$. It is interesting also to observe that the units of $\mathrm{BO}_{3}$ inside the $\mathrm{MRO}$ are also converted to the $\mathrm{BO}_{4}$ asymmetric units. The O-O correlations are included in the post shoulder of the first main peak.

In the third sample containing $22.5 \mathrm{WO}_{3}$ mole $\%$ the first coordination shells are very nearly of the same trend as the previous sample. The role of $\mathrm{Li}_{2} \mathrm{O}$ and $\mathrm{WO}_{3}$ is still counterpart in increasing the matrix order inside the SRO region. The $\mathrm{O}-\mathrm{O}$ correlations are found at $2.71 \AA$ with coordination number about 4.0. The presence of $\mathrm{B}-\mathrm{O}$ correlations in form of $\mathrm{NBO}$ and $\mathrm{BO}$ types are observed at $3.161 \AA$ and $3.581 \AA$ respectively; within the same noted values in the preceding sample. In the fourth sample containing $30 \mathrm{~mole} \%$ of $\mathrm{WO}_{3}$, the first observed distance is at $\sim 1.331 \AA$ which is attributable to B-O pairs arranged in the form $\mathrm{BO}_{3}$ instead of $\mathrm{BO}_{4}$ as reported above. This clearly reveals the cycling role of $\mathrm{Li}$-atoms inside the $\mathrm{Li}_{2} \mathrm{O}$ (as a modifier) in linking both of $\mathrm{B}-\mathrm{O}$ and $\mathrm{W}-\mathrm{O}$ inside the matrix and also the modifier ability to change $\mathrm{BO}_{3} \rightarrow \mathrm{BO}_{4} \rightarrow \mathrm{BO}_{3}$ with the enhancement of its ratio introduced in the glass. The next shell which always belongs to $\mathrm{W}-\mathrm{O}$ linked pairs is also declared at a shorter distance compared to its position reported above, $1.73 \AA$, and arranged in the form $\mathrm{WO}_{5}$. The B-B pairs are observed also at a shorter distance $2.328 \AA$. As a consequence an increased order inside the SRO region is observed when the ratio of $\left(\mathrm{WO}_{3}\right)$ reaches 22.5 mole \% and above this value an increased disorder is noted. Also an increased order can be noted inside the MRO region in the same previous range of $\mathrm{WO}_{3} \mathrm{~mole} \%$; in form of stretched distances of $\mathrm{NBO}$ and $\mathrm{BO}$ correlations, as given at $3.25 \AA$ (non-resolved shoulder) and 3.65 $\AA$. The presence of both $\mathrm{BO}_{3}$ of $\mathrm{NBO}$ type and $\mathrm{BO}_{4}$ connected units of $\mathrm{BO}$ are counter parting inside MRO in the studied amorphous systems. 
The last two specimens of higher $\mathrm{WO}_{3}$ ratios (32.5 and 33.75 mole $\%$ of $\mathrm{WO}_{3}$ ) have more or less the same RDF trend. The B-O linked pairs are assigned at $1.381 \AA$ (as a shoulder in form of $\mathrm{BO}_{3}$ ) and $\mathrm{W}-\mathrm{O}$ are seen at $1.801 \AA$ (in form of $\mathrm{WO}_{5}$ ). Both of $\mathrm{B}-\mathrm{B}$ and $\mathrm{O}-\mathrm{O}$ correlations are observed at $2.56 \AA$ and $2.89 \AA$ (of coordination numbers 3.144 and 1.81) respectively. The B-O bonds of NBO and $\mathrm{BO}$ are predicted at $3.182 \AA$ and $3.481 \AA$ having a coordination number of about 3.0 which confirms our notation of the conversion of $\mathrm{BO}_{3}$ to $\mathrm{BO}_{4}$ and finally evolution of $\mathrm{BO}_{3}$ units inside the $\mathrm{MRO}$ of the investigated glasses.

It should be noted that the discrepancy in W-O connected pairs regarding their bond lengths and also their coordination numbers among the given samples may be interpreted in terms of $\mathrm{WO}_{3}$ matrix complexity involving its solubility in the borate matrix [8], and also in terms of the amorphous matrix, lithium tungstate borate solubility and strength in regarding the existence of non-bridging oxygen's or its absence in the MRO of the investigated network [8]. The observed gradual decrease in the coordination number of $\mathrm{W}-\mathrm{O}$ pairs with the increase in $\mathrm{B}_{2} \mathrm{O}_{3}$ weight ratios may refer to the decreased stability in $\mathrm{W}-\mathrm{O}$ linked pairs and the reason is mainly due to the role of both $\mathrm{WO}_{3}$ and $\mathrm{Li}_{2} \mathrm{O}$ as a modifiers in the formed network [15], beside the role of $\mathrm{B}_{2} \mathrm{O}_{3}$ which also can be considered as a modifier when its concentration is more appreciable. The deficiency in the coordination of oxygen around $\mathrm{W}$-atoms will give an indication to the coloration behavior in these glassy systems [9-11].

It should be noted also that the shortening of some B-O bonds $(1.324 \AA)$ in the basic structural units inside the SRO region as given in sample four $\left(\mathrm{WO}_{3}=30\right.$ mole \%) is explained as NBO type B-O correlations as noted by Wright et al. for $\mathrm{Li}_{2} \mathrm{O}-\mathrm{B}_{2} \mathrm{O}_{3}$ [18]. It was observed from our obtained results that the bond length and the atomic coordination's of the atomic correlations B-O, B$\mathrm{B}$ and $\mathrm{O}-\mathrm{O}$ in both SRO and MRO are in good agreement with many other workers [7] although we are dealing in this work with a ternary complex system that have a variable range of $\mathrm{WO}_{3}$.

In reality many publications are found for the optical and electrical studies for the present investigated ternary system $[19,20]$ and rarely found published works concerning its structure. The extracted RDF structural parameters are collected in Table (2) for the investigated six samples for the comparison. 
Table (2): $\mathrm{RDF}$ (observed) extracted structural parameters of a- $\mathrm{Li}_{2} \mathrm{O}-\mathrm{WO}_{3}-\mathrm{B}_{2} \mathrm{O}_{3}$ with $\mathrm{WO}_{3}=17.5,20,22.5,30,32.5,33.75$ mole\% respectively.

\begin{tabular}{|c|c|c|c|c|c|c|c|c|c|c|c|c|c|}
\hline Sample & $\mathrm{R}_{1} \AA$ & $\mathrm{N}_{1}$ & $\mathrm{R}_{2} \AA$ & $\mathrm{N}_{2}$ & $\mathrm{R}_{3} \AA$ & $\mathrm{N}_{3}$ & $\mathrm{R}_{4} \AA$ & $\mathrm{N}_{4}$ & $\mathrm{R}_{5} \AA$ & $\mathrm{N}_{5}$ & $\mathrm{R}_{6} \AA$ & $\mathrm{N} 6$ & $\mathrm{R} 7 \AA$ \\
\hline W17.5 & 1.489 & 3.00 & 1.701 & 2.551 & 2.131 & 2.65 & 2.544 & 2.85 & 2.900 & 1.85 & $3.299,3.811$ & 2.850 & 4.118 \\
\hline Pair type & B-O & & W-O & & W- $\mathrm{O}_{2}$ & & B-B & & O-O & & BO $_{3}, \mathrm{BO}_{4}$ form & & \\
\hline W20 & 1.497 & 2.710 & 2.00 & 5.958 & 2.548 & 2.580 & 2.819 & 2.395 & 3.136 & 2.491 & 3.581 & & 4.359 \\
\hline Pair type & B-O & & W-O & & B-B & & O-O & & B-O & & B-O(BO $\left.\mathrm{BO}_{3}\right)$ & 2. & \\
\hline W22.5 & 1.499 & 3.921 & 1.988 & 6.164 & 2.391 & 2.591 & 2.711 & 3.85 & 3.161 & 3.611 & 3.581 & & 4.863 \\
\hline Pair type & B-O & & W-O & & B-B & & O-O & & B-O & & B-O $\left(\mathrm{BO}_{4}\right)$ & & \\
\hline W=30 & 1.331 & 3.011 & 1.730 & 4.755 & 2.328 & 3.35 & 2.650 & 4.307 & 3.25 & 2.68 & 3.650 & & \\
\hline Pair type & B-O & & W-O & & B-B & & O-O & & B-O & & B-O $\left(\mathrm{BO}_{4}\right)$ & & \\
\hline W=32.5 & 1.381 & 2.651 & 1.801 & 5.011 & 2.561 & 3.144 & 2.89 & 1.81 & 3.182 & 2.995 & 3.481 & & \\
\hline Pair type & B-O & & W-O & & B-B & & O-O & & B-O & & B-O $\left(\mathrm{BO}_{3}\right)$ & & \\
\hline
\end{tabular}

$\mathrm{R} \pm .05 \AA, \mathrm{N} \pm 0.35$

Figures ( $3 \& 4)$, which are supported from Doweidar [12], show the variation of $\mathrm{WO}_{3}(\mathrm{~mole} \%)$ with both the activation energy and the conductivity $\log \sigma$ respectively, one can observe that, the activation energy decreases with the increase of the molar ratio of $\mathrm{WO}_{3}$ to about $27.5 \mathrm{~mole} \%$ and after that value $\mathrm{E}$ will suffer an increase. As well as the change in $\log \sigma$ versus $\mathrm{WO}_{3}($ mole\%) had increased with the enhancement of $\mathrm{WO}_{3}$ molar ratio up to $27.5(\mathrm{~mole} \%)$ and after that value $\log \sigma$ going to decrease again with the continuous increase in $\mathrm{WO}_{3}(\operatorname{mole} \%)$. The increase in $\log \sigma$ and the decrease in $\mathrm{E}$ with the increase in the $\mathrm{WO}_{3}$ molar ratio in these two figures indicate to the order increase in the studied amorphous network inside the noted range of $\mathrm{WO}_{3}(17.5-27.5 \mathrm{~mole} \%)$. These findings are confirmed and giving good consistency with the reported results by Peng-nian et al. [17] and confirmed in our study in the given table 2 above, both tungsten ions $\mathrm{W}^{6+}$ and $\mathrm{W}^{5+}$ co-exist in these glasses with $\mathrm{WO}_{3}$ content less than $35 \mathrm{~mole} \%$ and the percentage of $\mathrm{W}^{6+}$ ion increase by increasing the $\mathrm{WO}_{3}(\mathrm{~mole} \%)$, in the considered range. Increasing the percentage of $\mathrm{W}^{6+}$ means an increase in the network order. This is confirmed also by Peng-nian et al. [17] who reported that: with the increase of $\mathrm{WO}_{3}(\operatorname{mole} \%)$, the value of the optical band gap $\left(\mathrm{E}_{\mathrm{g}}\right)$ decreased which indicates an increase in the network order and increase in the O-W-O correlations stability. Both of activation energy $\left(E_{g}\right)$ and $\log \sigma$ for the investigated samples can be plotted against W-O bond length, which gives clearly a linear relationship between $\mathrm{W}-\mathrm{O}$ versus $\mathrm{E}_{\mathrm{g}}$ and $\log \sigma$ respectively. 


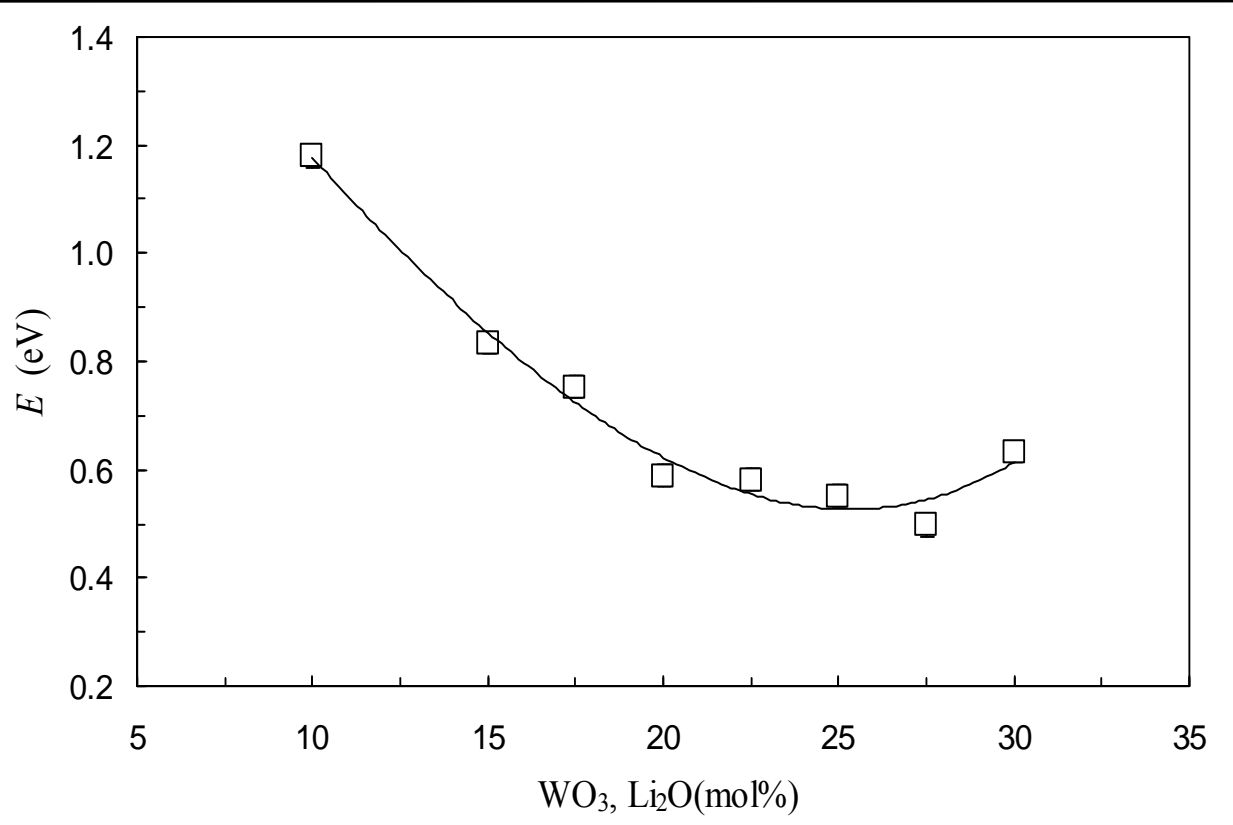

Fig.(3): The activation energy, E, versus $\mathrm{WO}_{3}($ mole \%) for the studied samples.

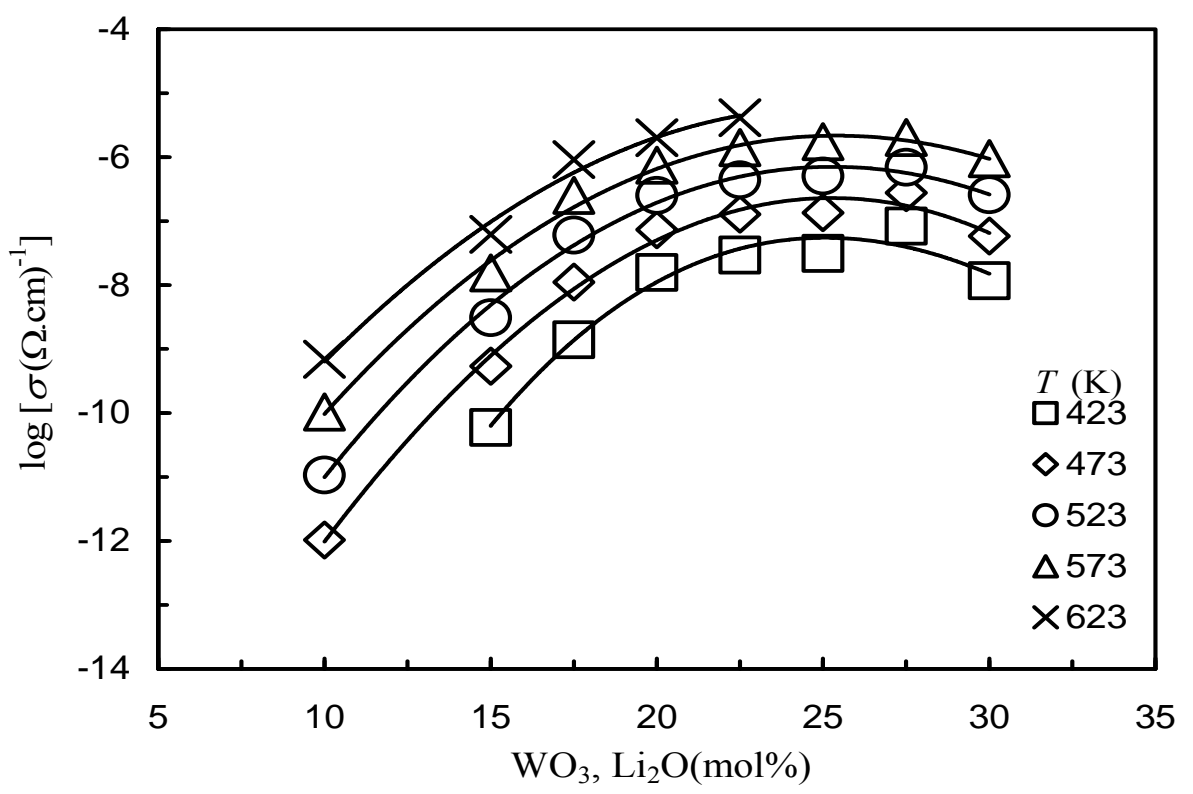

Fig.(4): $\log \sigma$ versus $\mathrm{WO}_{3}$ (mole \%) for the studied samples 


\section{Conclusions:}

The role of $\mathrm{Li}_{2} \mathrm{O}$ in the network as a modifier was found to convert cyclically $\mathrm{BO}_{3}-\mathrm{BO}_{4}-\mathrm{BO}_{3}$ forms of both symmetric and anti-symmetric correlated distances inside MRO and also SRO. The $\mathrm{Li}^{+}$ion was able to connect both B-O and W-O inside the matrix. The degree of network disorder decreased largely with increasing the mole ratios of $\mathrm{B}_{2} \mathrm{O}_{3}(50-65$ mole \%) and also in the low borate ratios (5-30 mole \%). The MRO region had both bridging and nonbridging (BO \& NBO) connected oxygen's of longer distance of correlation for the first type (BO). The activation energy and the electrical conductivity are measured and good correlated with the structural extracted information's for the studied glasses.

\section{Acknowledgement:}

Great deep sincere thanks are directed to Prof. H. Doweidar, Mansoura University for supplying me with the samples activation energy and conductivity [12]. The Author is acknowledging and introducing the great deep thanks to Prof. Karimat El-Sayed, Ain Shams University for her fruitful discussions and revising the text.

\section{References:}

1. M. Wollenhaupt, H. Ahrens, P. Frobel, K. Barner, E. R. Giessinger and R. Braunstein, J. Non-Crystalline Solids 194, 191 (1996).

2. S. K. Deb, Phil. Magazine, 22, 801 (1973).

3. R. braunstein and K. Barner, Solid State Commun. 28, 847 (1978).

4. R. braunstein and K. Barner, Solid State Commun. 33, 941 (1980).

5. B. W. Faughnan, R. S. Crandall and P. M. Heyman, RCA Review 36, 177 (1975).

6. Ch. Ruf, K. Barner and R. Braunstein, Solid State Commun. 54, 111 (1985).

7. N. Umesaki, Y. Kita, T. Iida, K. Handa, S. Kohara, K. Suzuya, T. Fukunaga and M. Misawa, Phys. Chem. Glasses 41 (5), 304 (2000).

8. R. M. Abdelouhab, R. Braunstein and K. Barner, J. Non-Crystalline Solids 108, 109 (1989).

9. R. B. Goldner, D. H. Mendelson, J. Alexander, W. R. Henderson, D. Fitzpatrick, T. F. Haas, H. H. Sample, R. D. Rauth, M. A. Parker and T. L. Rose, Appl. Phys. Letters 43 (12), 1093 (1983).

10. C. M. Lampert and C. G. Granqvist, "Large-Area Chronogenics; Materials and Devices for Transmittance Control" IS4, SPIE OPT-Engr. Press, Bellingham (1990). 
11. C. G. Granqvist; "Materials Science for Solar Energy Conversion System", edited by C. G. Granqvist (Pergamon Oxford) p. 106 (1991).

12. H. Doweidar, Mansoura University, Personal communication.

13. J. Krogh-Moe, J. Non-Crystalline Solids, 1, 269 (1969).

14. R. L. Mozzi and B. E. Warren, J. Appl..Crystallogr. 3, 251 (1970).

15. E. A. Porai-Koshits and A.C.Wright, "Proc. Second Int. Conf. on: Borate Glasses, Crystals, and Melts", 50 (1997).

16. A. Abou Shama, Egypt. J. of Solids, 28(2), 337 (2005).

17. Peng-nian Huang, Xi-huai-Huang and Fu-xi Gan, Solid State Ionics 57, 169 (1992).

18. Adrian C. Wright, Joanna L. Shaw, Roger N. Sinclair, Natalia M. Veishcheva, Boris A. Shakhmatkin and Charlie R. Scales, J. Non-crystalline Solids, 345 \& 346, 24 (2004).

19. M. Wollenhaupt, H. Ahrens, P. Frobel, K. Barner, E. R. Giessinger and R. Braunstein, J. Non-Crystalline Solids, 194, 191 (1996).

20. J. Maab, H. Ahrens, P. Frobel, K. Barner, E. R. Giessinger and R. Braunstein, Solid State Comminucations, 87(6), 567 (1993). 